Proceedings of the XXIII Conference on Applied Crystallography, Krynica Zdrój, Poland, September 20-24, 2015

\title{
Characterization of Precipitates in Aluminium Alloy 6013 after Cold-Rolling and Annealing
}

\author{
M. BIEDA AND A. JARZĘBSKA* \\ Institute of Metallurgy and Materials Science, Polish Academy of Sciences, Krakow, Poland
}

\begin{abstract}
The aim of the present work was to observe changes in precipitations during annealing after cold-rolling. Series of the samples from cold-rolled AA6013 were prepared and compared to undeformed samples. The samples were annealed at the temperatures equal to $260,490^{\circ} \mathrm{C}$ for undeformed state and at 280,360 , and $530{ }^{\circ} \mathrm{C}$ for cold-rolled state. For investigation thin foils were prepared. Chemical composition and crystal structure of precipitates was analysed and described using transmission electron microscopy imaging, X-ray energy-dispersive spectroscopy and selected-area diffraction techniques. The researches indicated that low annealing temperatures caused dissolution of metastable $\beta$ and $Q$ phases. With increasing temperature there also occurred growth of $Q$ phase. At highest annealing temperatures there were noticed precipitations of $\beta$ phase again. Microstructural observation also revealed an impact of those particles on recrystallization processes.
\end{abstract}

DOI: 10.12693/APhysPolA.130.988

PACS/topics: 61.66.Dk, 68.37.Lp

\section{Introduction}

The 6xxx series aluminium alloys are materials with very good strength, good formability, and the best corrosion resistance among other aluminium alloys. In order to improve their strength and hardness the addition of copper was applied [1-3]. The AA6013 alloy is an example of $6 \mathrm{xxx}$ series alloys with addition of copper.

Precipitations play an essential role in improving mechanical properties. They constitute obstacle to the movement of dislocations which leads to strengthening of the alloy. The reaction between particles and dislocations depends on size, distribution, and shape of precipitations. These factors can determine which kind of strengthening mechanism will occur. The main influence on changes of character of particles has temperature. With its increase movement of atoms is higher which can leads to forming new precipitations or cause transformation one particle into another [4].

The purpose of this work was to investigate the influence of annealing temperature on stability and type of precipitates in plastically deformed AA6013 alloy. Although there are some works about the precipitations during ageing $[2,3,4-6]$, there are no consistent works about the particles transformations during recrystallizations annealing of this alloy and deconvolution of the overlapped processes.

\section{Experimental procedure}

Material used in this work was aluminium alloy 6013 whose composition is shown in Table I.

Samples of tested material were supersaturated at $530^{\circ} \mathrm{C}$ for $1 \mathrm{~h}$ and quenched in water. Then they were

\footnotetext{
*corresponding author; e-mail: a.jarzebska@imim.pl
}

TABLE I

Chemical composition [wt\%] of tested AA6013.

\begin{tabular}{c|c|c|c|c|c|c}
\hline \hline $\mathrm{Mg}$ & $\mathrm{Si}$ & $\mathrm{Cu}$ & $\mathrm{Mn}$ & $\mathrm{Fe}$ & $\mathrm{Cr}, \mathrm{Ti}, \mathrm{Zn}$ & $\mathrm{Al}$ \\
1.15 & 1.0 & 1.1 & 0.3 & 0.5 & 0.15 & bal.
\end{tabular}

aged at $165^{\circ} \mathrm{C}$ for 5 days. Subsequently alloy was deformed by reversible cold rolling up to $90 \%$ (up to $1 \mathrm{~mm}$ in thickness) on Quatro Duo machine. From thus prepared material samples were cut for testing. For comparison, samples in undeformed and deformed states were investigated. In order to observe changes in the material under annealing, samples were heated in Netzsch thermomechanical analyser TMA 402 F1 Hyperion at 260, $490^{\circ} \mathrm{C}$ for undeformed samples and at 280,360 , and $530^{\circ} \mathrm{C}$ for rolled state. Annealing temperatures were selected based on calorimetric test, in that way to analyse changes in picks marked in Fig. 1 and compared to nonannealed undeformed and deformed samples.
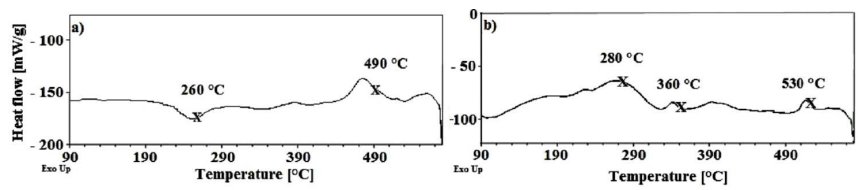

Fig. 1. Calorimetric curves obtained for AA6013 (a) after supersaturation and ageing and (b) cold-rolled with reduction $90 \%$.

Microstructure observations of the samples were performed using TECNAI G2 F20 transmission electron microscope (TEM) from section cut parallel to the rolling direction. Chemical composition of particles was studied by EDS during observation STEM HAADF. Electron diffractions patterns were analysed using KikSpot Software [7]. 


\section{Results}

The carried out researches allowed to distinguish the precipitations in AA6013 and confirmed bimodal structure typical for this alloy. The large particles with the size over $1 \mathrm{\mu m}$ were observed in all investigated samples and characterized as primary particles. The ovalshaped precipitates with size 1-4 $\mu \mathrm{m}$ (containing $\mathrm{Al}$ and Si) were present. Apart of them ones with the irregular shape, size of 1 to $5 \mathrm{\mu m}$ were also noticed. They contained mainly $\mathrm{Al}, \mathrm{Mn}, \mathrm{Fe}$, and $\mathrm{Si}$ and are described as casting $\alpha$ phase [5]. The different kinds of small particles of other phases were also distinguished and were related to the DSC peaks. One of them, which was stable for all investigated samples had ellipsoidal shape with size 50-200 nm, consisted of $\mathrm{Al}, \mathrm{Mn}, \mathrm{Fe}$, and Si (with high $\mathrm{Mn} /$ Fe ratio) and can be considered as a dispersoids of $\alpha$ phase forming during supersaturation [8]. These phases are shown in Fig. 2.
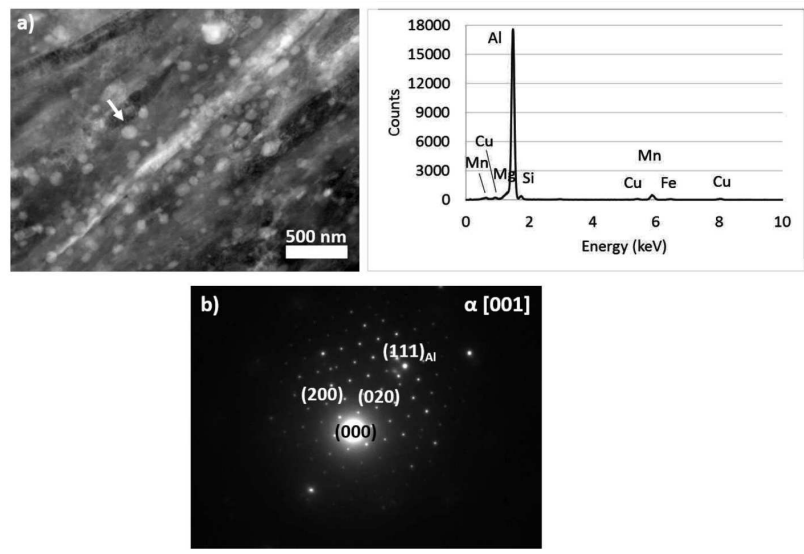

Fig. 2. Example of $\alpha$ dispersoids (a) STEM image and EDS spectrum and (b) diffraction pattern.
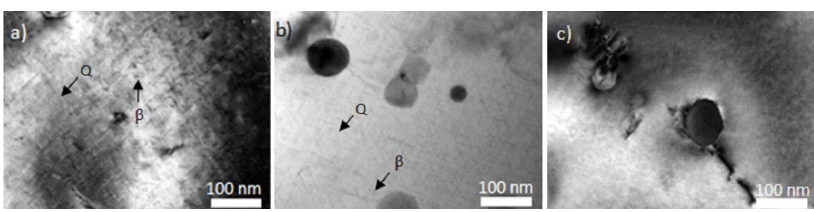

Fig. 3. Microstructure TEM BF of undeformed samples and (a) non-annealed, (b) annealed at $260^{\circ} \mathrm{C}$ and (c) annealed at $490^{\circ} \mathrm{C}$.

Two kinds of particles formed after supersaturation and annealing were featured - rod-shaped with size 50$200 \mathrm{~nm}$ and containing majority of $\mathrm{Al}, \mathrm{Mg}$, $\mathrm{Si}, \mathrm{Cu}$, can be distinguished as a $Q$ phase $\left(\mathrm{Al}_{3} \mathrm{Mg}_{9} \mathrm{Si}_{7} \mathrm{Cu}_{2}\right)[5,6,9$ 11]. Moreover in undeformed and non-annealed and undeformed and annealed in $260^{\circ} \mathrm{C}$ samples needle-shaped precipitates were observed and can be considered as metastable $\beta\left(\beta^{\prime \prime}-\mathrm{Mg}_{5} \mathrm{Si}_{6}, \beta^{\prime}-\mathrm{Mg}_{9} \mathrm{Si}_{5}\right.$ [6]) and $Q$ $\left(Q^{\prime}-\mathrm{Al}_{38} \mathrm{Mg}_{8.6} \mathrm{Si}_{7} \mathrm{Cu}_{1}[6]\right)$ phases. They are marked in Fig. 3. Figure 4 exhibits electron diffraction pattern of metastable $\beta$ phase.
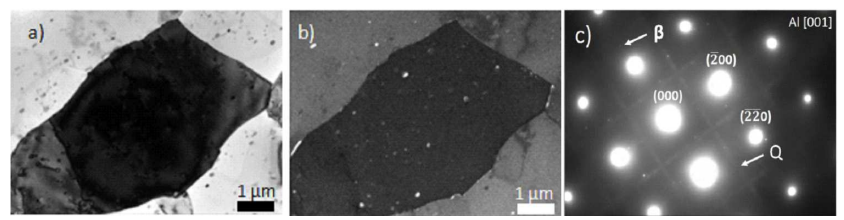

Fig. 4. The microstructure of undeformed and nonannealed sample: (a) bright field image, (b) dark field image and (c) diffraction pattern of metastable $\beta$ and $Q$ phases.

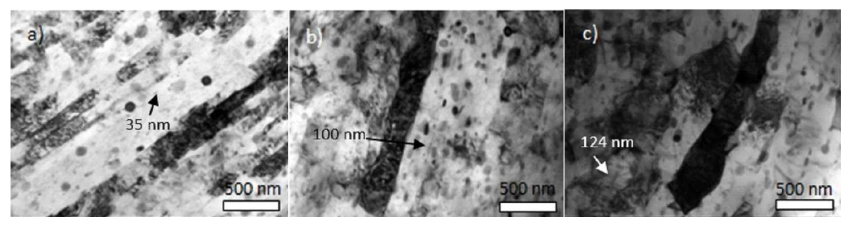

Fig. 5. TEM BF images of cold-rolled samples and (a) non-annealed, (b) annealed at $280^{\circ} \mathrm{C}$ and (c) annealed at $360^{\circ} \mathrm{C}$.

It was noticed that increase of temperature caused growth of $Q$ phases precipitates in both investigated cases (up to $600 \mathrm{~nm}$ ) (Figs. 5, 6). Differentiation between $Q$ and $Q^{\prime}$ was difficult because of almost the same crystal structure (lattice parameters: $a=b=1.032, c=0.405$, $\gamma=120^{\circ}$ and $a=b=1.039, c=0.402, \gamma=120^{\circ}$, respectively and both phases have HZ $P \overline{6}$ space group [6]). The transformation of $Q^{\prime}$ phase into $Q$ could be noticed by determination of shape and size of particles.

In case of $\beta$ phases (stable $-\mathrm{Mg}_{2} \mathrm{Si}[6]$ and metastable $\left.\beta^{\prime}, \beta^{\prime \prime}\right)$ the influence of the annealing temperature is significant. They were stable till $260^{\circ} \mathrm{C}$ for undeformed sample and till $280^{\circ} \mathrm{C}$ for rolled state. The increase of temperature caused dissolution of metastable $\beta$ phases. These changes can be observed in Figs. 3 and 5 . For non-deformed samples dissolution corresponds to strong exothermic peak presented in the DSC diagram, for de-

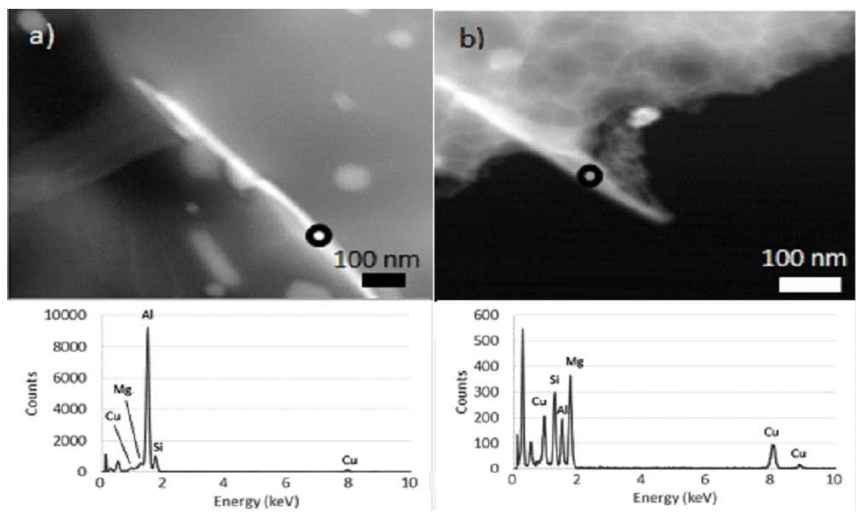

Fig. 6. STEM HAADF image and EDS spectra of $Q$ phase in (a) undeformed and annealed at $490^{\circ} \mathrm{C}$ sample and (b) rolled and annealed at $530^{\circ} \mathrm{C}$ sample. 


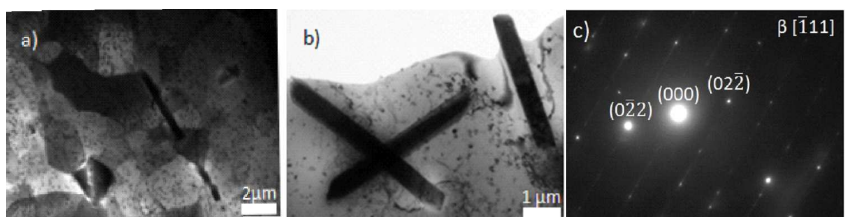

Fig. 7. TEM BF images of stable $\beta$ phase (a) undeformed and annealed at $490^{\circ} \mathrm{C}$ and (b) rolled and annealed at $530^{\circ} \mathrm{C}$ and (c) diffraction pattern of stable $\beta$ phase.

formed samples this peak is convoluted with peaks corresponding to recrystallization process, and both processes are partly overlapped.

Besides, increase of temperature up to $490^{\circ} \mathrm{C}$ for undeformed samples caused precipitation of stable large $\beta$ phase. Similar behaviour can be observed for deformed samples. In their case increase of the temperature to $530^{\circ} \mathrm{C}$ caused precipitation of large $\beta$ phases with lath shape, width about $500 \mathrm{~nm}$ and length up to $4 \mu \mathrm{m}$. In Fig. 7 large stable $\beta$ phases in both investigated cases are shown. This precipitation process corresponds to strong DSC peaks revealed in those temperatures ranges.

\section{Discussion and summary}

Obtained results allowed to perceive the influence of precipitations on the deformation and recrystallization process. Non-deformed samples had structure with equiaxed grains while deformed alloy was characterized with strongly elongated grains in rolling direction (Fig. 8b). After annealing at $280^{\circ} \mathrm{C}$ material possesses elongated grains in which recovery processes started and some new grains occurred in high deformation zones, next to large particles $[12,13]$. The behaviour of the material during annealing can be explained by the sequence of precipitating. For the delay in recrystallization process is responsible the existence of small metastable precipitation of $\beta$ and $Q$ phases. Dissolution of $\beta$ phases and growth of $Q$ phases contributed to the fact that the further growth of grain size up to $360^{\circ} \mathrm{C}$ were mostly prevented by $\alpha$ dispersoids. Grain size in recrystallization process was especially restricted in perpendicular direction to rolling direction (Fig. 8c) [8]. Because of that, substantial grain growth can be observed for deformed sample after annealing at $530^{\circ} \mathrm{C}$ (Fig. 8d).

\section{Conclusions}

1. Investigated aluminium alloy 6013 had bimodal structure which consisted of large silicon particles and $\alpha$ (AlFeMnSi) phases which were considered as primary particles, small $\alpha$ dispersoids phases and two kinds of secondary phases $\beta$ and $Q$ and their metastable variants.

2. DSC peak observed for non-deformed alloy at temperature around $300^{\circ} \mathrm{C}$ corresponds to dissolution of $\beta^{\prime}$ phases and peak at $500{ }^{\circ} \mathrm{C}$ to precipitation of stable $\beta$ phases. The growth of $Q$ phases was observed with annealing temperature rise.
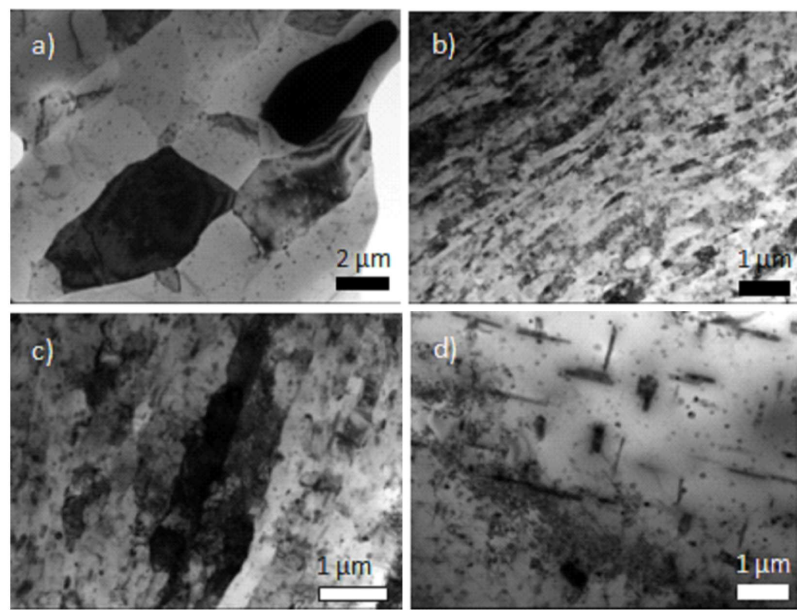

Fig. 8. TEM BF images of microstructures (a) undeformed and non-annealed sample, (b) rolled and nonannealed sample, (c) rolled and annealed at $360^{\circ} \mathrm{C}$ and (d) rolled and annealed at $530^{\circ} \mathrm{C}$.

3. In case of annealing of deformed alloys two stages of the recrystallization process were noticed. This was caused by numerous precipitations which occurred in these alloys.

\section{Acknowledgments}

This work was supported by the National Science Center (Poland) UMO -2011/03/D/ST8/04106.

\section{References}

[1] J. Hirsch, T. Al-Samman, Acta Mater. 61, 818 (2013).

[2] H. Demir, S. Gündüz, Mater. Des. 30, 1480 (2009).

[3] J. Dutkiewicz, L. Lityńska, Mater. Sci. Eng. A 324, 239 (2002).

[4] D.J. Chakarabarti, D.E. Laughlim, Prog. Mater. Sci. 49, 389 (2004).

[5] C. Barbosa, J.M.A. Rebello, O. Acselard, J. Dille, J.L. Delplancke, Z. Metallkd. 93, 208 (2002).

[6] W. Yang, L. Huang, R. Zhang, M. Wang, Z. Li, Y. Jia, R. Lei, X. Sheng, J. Alloys Comp. 514, 220 (2012).

[7] CrystOrient, KikSpot Software.

[8] L. Lodgaard, N. Ryum, Mater. Sci. Eng. A 283, 144 (2000).

[9] K. Matsuda, Y. Uetani, T. Sato, S. Ikeno, Metall. Mater. Trans. A 32, 1293 (2001).

[10] J. Douin, P. Donnadieu, T. Epicier, G.F. Dirras, A. Proult, J.F. Silvain, Mater. Sci. Eng. A 319-321, 270 (2001).

[11] F. Delmas, M.J. Casanove, P. Lours, A. Couret, A. Coujou, Mater. Sci. Eng. A373, 80 (2004).

[12] M. Bieda, K. Sztwiertnia, A. Korneva, T. Czeppe, R. Orlicki, Solid State Phenom. 163, 13 (2010).

[13] M. Bieda, J. Kawałko, F. Brisset, K. Sztwiertnia, IOP Conf. Series Mater. Sci. Eng. 82, 1 (2015). 